\title{
Relationship between Leg Strength and Balance and Lean Body Mass. Benefits for Active Aging
}

\author{
Alfonso Castillo-Rodríguez ${ }^{1, *}(\mathbb{D})$, Wanesa Onetti-Onetti ${ }^{2, *} \mathbb{D}$, Rui Sousa Mendes ${ }^{3}$ and \\ José Luis Chinchilla-Minguet ${ }^{4}$ \\ 1 Department of Physical Education and Sports, University of Granada, 18011 Granada, Spain \\ 2 Faculty of Education, UNIR, International University of la Rioja, 26006 Logroño, Spain \\ 3 Escola Superior de Educaçao, Instituto Politécnico de Coimbra, 3030-329 Coimbra, Portugal; \\ rmendes@esec.pt \\ 4 Department of Languages, Arts and Sports, University of Málaga, 29010 Málaga, Spain; jlchinchilla@uma.es \\ * Correspondence: acastillo@ugr.es (A.C.-R.); wanesa.onetti@unir.net (W.O.-O.); \\ Tel.: +34-958-24-43-77 (A.C.-R.)
}

Received: 28 January 2020; Accepted: 16 March 2020; Published: 18 March 2020

check for updates

\begin{abstract}
Physical activity (PA) can bring incalculable benefits to people throughout the aging process. The objective of this study was to determine the relationships between the leg and arm strength, body composition and balance of elderly people. Twenty-one people ( 9 men and 12 women) over 60 years of age voluntarily participated in this study. Bioimpedance tests were carried out to obtain body mass data, manual dynamometer tests and the lower limbs test were conducted to obtain strength values, and the stork balance stand test was conducted to assess static balance. As a result, medium-high correlation coefficients were obtained between the aforementioned dependent variables. The highest value corresponded to the relationship between the results of the dominant hand strength test (right hand in all participants) and the lean body mass (LBM) of the participant $\left(\mathrm{R}^{2}=75 \%\right.$, $p<0.001)$. The results indicated that strength capacity, recorded by dynamometry, and balance ability have a direct relationship with the body composition of the subject, especially with their lean body mass. These data suggest that a greater lean body mass can provide greater strength and balance in the elderly, so it would improve or have greater duration the functionality and independence of the person, thereby justifying direct benefits in people and indirect benefits in public administrations that finance these social issues.
\end{abstract}

Keywords: aging; physical activity; sustainability; strength; health and wellness; body composition

\section{Introduction}

Once maturity is reached by an individual and as they age, their physical ability progressively and inevitably deteriorates, and at the same time, various degenerative diseases may develop [1]. Maintaining an adequate level of muscular strength is considered necessary to independently perform daily activities [2]. A decrease in fat-free mass (FFM), initially caused by a loss of skeletal muscle mass as well as bone mineral, affects muscle strength and increases the risk of disability and weakness in the elderly population [3].

In addition, obesity is considered the second leading cause of preventable death (following tobacco use). Along with a sedentary lifestyle, obesity is one of the main risk factors for a large number of diseases and health problems, including hypertension, hypercholesterolemia, adult diabetes, coronary heart disease, certain types of cancer and many other chronic diseases [4]. There is evidence that regular physical activity (PA) can slow the degenerative processes typically associated with aging [5]. 
PA has been shown to an increase in bone density, and in general, regular vigorous PA at any age is believed to improve individuals' health [6].

One of the constant concerns on the part of public administrations is suffering from chronic diseases caused by changes in body composition (increase in fat mass, FM) [7]. In this sense, lean body mass (LBM) and FM are body composition states that vary constantly and are closely related to the aging process [8,9]. In addition, a strong relationship has been established between decreased muscle strength, physical capacity, quality of life and loss of fat-free mass. [10].

Aging can lead to variations in body composition when one is middle-aged and thereafter [11], including an increase in FM, a reduction in LBM $[12,13]$ and a loss of height due to compression of the vertebrae and a progressive curvature of the back [14]. Moreover, from the age of approximately 65 to $75-80,25 \%$ of an individual's total muscle mass is lost [15].

Previous studies have investigated the benefits of physical activity on body composition [16-21], cardiovascular risk factors [20,21] and physical condition [17,22,23]. Physical condition encompasses the so-called physical qualities, which include resistance in its different manifestations, muscle strength, speed, joint mobility, coordination qualities and balance. (However, all studies indicated that participants were taking medications.) These physical qualities have been proven to impact an individual's health, but scientific evidence shows that aerobic capacity and strength in particular have the most relevance [24].

On the other hand, authors must consider that performing physical activity also plays an important role in total daily energy expenditure, which contributes to the regulation of body weight $[25,26]$. In addition to physical benefits, physical activity is associated with psychosocial welfare benefits [27]. While technological advances have led to an increase in the life expectancy of people in developed countries, they have also led to the emergence of diseases caused by sedentary lifestyles. Thus, there is a worldwide interest in preventing such diseases and promoting health through the implementation of active lifestyles [28]. So, the objectives of this study were to determine the relationships between the leg and arm strength, body composition and balance of elderly people, and to create formulas that can predict results of physical tests through body composition values such as LBM.

\section{Materials and Methods}

\subsection{Participants}

Twenty-one people over 60 years old, including nine men $(63.9 \pm 1.1$ years; $65.0 \pm 12.5 \mathrm{~kg}$; $162.0 \pm 7.6 \mathrm{~cm})$ and twelve women $(62.1 \pm 2.9$ years; $70.5 \pm 10.2 \mathrm{~kg} ; 164.0 \pm 8.1 \mathrm{~cm})$, were selected. All participants were residents in the province of Malaga. All were fully capable of moving both their arms and legs, and did not suffer from any disease or pathology that could affect the results of the tests that were to be carried out. The objectives of the study were explained, and voluntary consent was obtained from each participant once it was determined that they met the inclusion criteria. This study was performed in accordance with the provisions of the Helsinki Declaration [29], and the Ethics Committee of the University of Malaga approved the completion of this study.

The inclusion criteria were an age older than 60 years, and the absence of a pathology related to the musculoskeletal or cardiorespiratory system that could affect the results of the tests. In addition, individuals suffering from high blood pressure were excluded, since all of them were taking medications that may have affected the outcomes of the strength tests.

\subsection{Instruments}

A TANITA scale (SC-230, Japan) was used to calculate the electrical bioimpedance. The standard technique was followed, which is detailed in another study as follows [6]:

- Do not eat or drink for at least $4 \mathrm{~h}$ prior to testing.

- Do not practice any PA for at least $4 \mathrm{~h}$ prior to testing.

- Do not consume alcohol for at least $24 \mathrm{~h}$ prior to testing. 
- Empty one's bladder 30 min before testing.

- Remove any metal objects, such as jewellery and watches, prior to testing.

The Grip Strength Dynamometer (Takei Kiki Kogyo, Tokyo, Japan) was used for hand dynamometry (5401 Grip-D, Takei Scientific Instruments ${ }^{\circledR}$ ). The measurement protocol for this instrument was followed, which involved holding the arm extended and near the body, with the dynamometer screen facing outward. Subsequently, the participant was asked to generate a strong and progressive pressure against the dynamometer handle (approximately 3 seconds). This test was performed twice for each participant, with a one-minute break between the two attempts. The best result obtained (in $\mathrm{kg}$ ) in the two attempts was used for analysis [30].

To measure the dynamics of the lower extremities, a specific dynamometer was used. The protocol was as follows: the participant stood on the support platform of the dynamometer with their legs semiflexed (to an angle of $150^{\circ}$, measured with a universal goniometer, $0-180^{\circ}$, Stainless Steel), trunk in an upright position, arms extended and hands maintaining the grip. The goal of the test was for an individual to extend their leg for approximately three seconds without losing their grip or upright posture. The needle of the dynamometer indicated the maximum force. The test was performed twice for each participant, and one minute of rest between trials was provided. The best result obtained (in $\mathrm{kg}$ ) in the two attempts was used for analysis [30].

The stork balance stand test was used to measure each participant's balance while they stood on one foot. Each subject stood barefoot on a carpet with their hands on their waist, and placed one foot on the inside of the knee of the other leg for support. The recorded time began when the participant lifted one foot off of the ground [31]. The recorded time ended when one or both hands separated from the waist, the support foot changed position (moved), or the foot resting on the opposite knee lost contact. The results of the stork balance stand test is explained in Table 1.

Table 1. Categories of results from the stork balance stand test.

\begin{tabular}{cc}
\hline Category & Seconds \\
\hline Excellent & $>50$ \\
Good & $40-50$ \\
Mean & $25-39$ \\
Regular & $10-24$ \\
Poor & $<10$ \\
\hline
\end{tabular}

\subsection{Procedure}

The participants were given an informed consent form explaining what would be involved in this study. Once the participants had understood the study and signed the form, they were administered a medical questionnaire to verify that they met the inclusion criteria and to collect sociodemographic data (age, sex, work performed, etc.). The questionnaire and tests were administered on the same day, so the timing of the study protocol was coordinated with the participants' schedules. The order of the tests was as follows: the assessments of body composition (bioimpedance); the grip strength dynamometer test; the stork balance stand test; and the strength dynamometer lower limb test. With each participant, the research team performed the tests in a maximum time of $10 \mathrm{~min}$.

\subsection{Statistical Analysis}

For the statistical analysis of the variables, the Shapiro-Wilk test was performed to test the normality of the data set. After the sample data were confirmed to follow a normal distribution, quantitative descriptive analysis (mean, standard deviation, variance, maximum, minimum) was performed. Subsequently, the Pearson correlation coefficient was used to analyse the quantitative variables. Finally, we proceeded to perform linear regression tests (stepwise) to determine the coefficient of determination between the dependent variables analysed. For all analyses, the statistical programs 
SPSS 23 for Windows (SPSS Inc., Chicago) and Microsoft Excel 2010 (Microsoft Corp, Redmond, Washington, USA) were used.

\section{Results}

Table 2 shows the correlation coefficients corresponding to the relationships between limb strength and body composition. There was a moderate correlation between leg strength and the body composition variables. There was a strong correlation between manual prehensile strength (right hand, which coincides with the dominant hand) and LBM and total body water. These correlations were similar to those of the nondominant hand (left hand, predominantly), although the latter correlations were weaker.

Table 2. Pearson's correlation coefficient.

\begin{tabular}{cccc}
\hline & $\begin{array}{c}\text { Strength: Left Hand } \\
(\mathbf{k g})\end{array}$ & $\begin{array}{c}\text { Strength: Right Hand } \\
\mathbf{( k g})\end{array}$ & $\begin{array}{c}\text { Strength: Legs } \\
\mathbf{( k g )}\end{array}$ \\
\hline Impedance (Ohm) & $-0.594^{* *}$ & $-0.671^{* *}$ & $-0.519^{* *}$ \\
Fat Mass (FM) (\%) & $-0.609^{* *}$ & $-0.455^{* *}$ & $-0.445^{* *}$ \\
Lean Body Mass (LBM) (kg) & $0.782^{* *}$ & $0.833^{* *}$ & $0.705^{* *}$ \\
Total Water (kg) & $0.787^{* *}$ & $0.842^{* *}$ & $0.699^{* *}$ \\
\hline & ${ }^{*} p<0.05 ;^{* *} p<0.01$ &
\end{tabular}

Next, the relationship between leg strength and balance performance was studied (Figure 1). The Pearson correlation test showed a moderate correlation between both variables $(r=0.489, p=0.025)$. Subsequently, the coefficient of determination suggested that the result of the equilibrium test was explained by $16 \%$ of the variance of leg strength $\left(R^{2}=0.162 ; p<0.05\right.$; Formula 1$)$.

$$
\text { Test Stork stand }=1.7728+(0.0119 * \text { Strenght legs })
$$

Formula 1. Formula for predicting balance performance from leg strength.

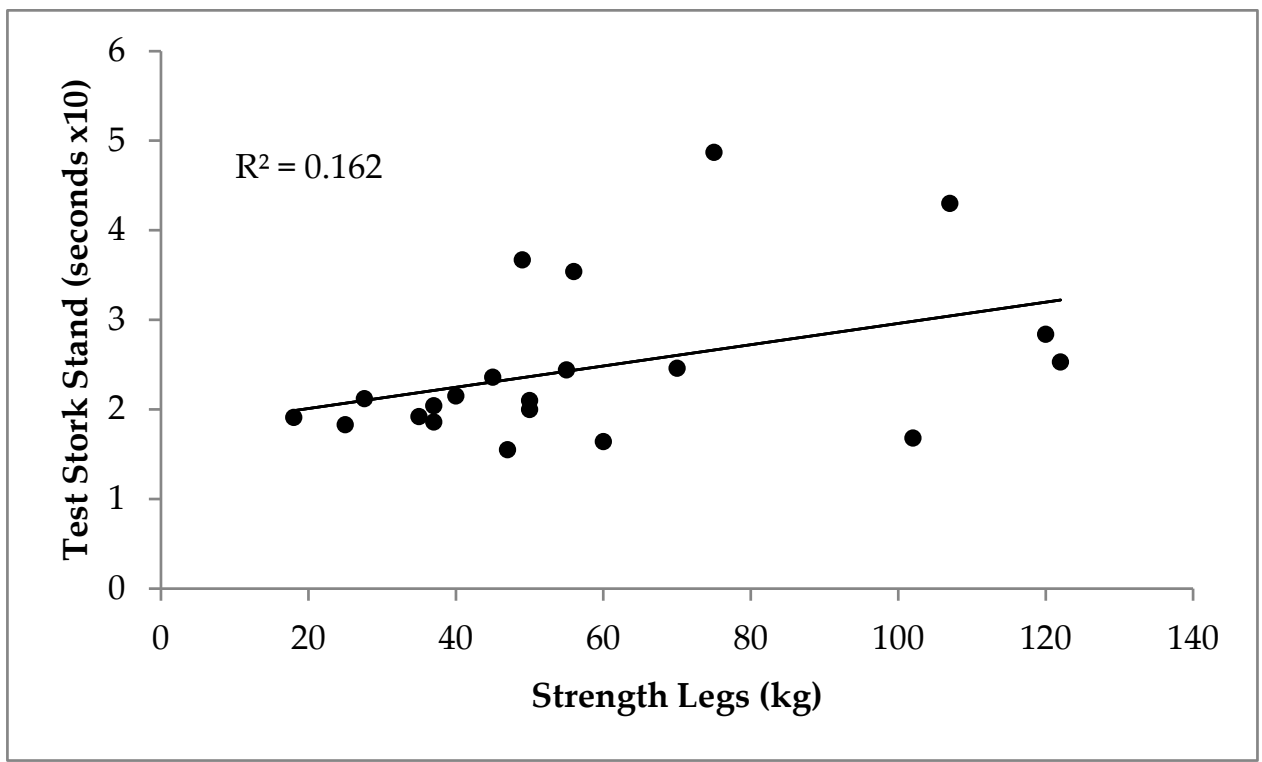

Figure 1. Relationship between leg strength and balance performance.

On the other hand, the relationship between the LBM of an elderly person and the leg strength and manual prehensile strength generated by the dominant hand was calculated (Figures 2 and 3, respectively). The coefficients of determination show that $57 \%$ and $75 \%$ of the strength in the legs 
and in the dominant hand, respectively, are explained by the $\operatorname{LBM}\left(\mathrm{R}^{2}=0.571, p<0.001 ; \mathrm{R}^{2}=0.745\right.$, $p<0.001$; Formulas 2 and 3).

$$
\text { Strength Legs Test }=-47.808+(2.166 * \text { LBM })
$$

Formula 2. Formula for predicting leg strength from the LBM determined by impedance.

$$
\text { Strength Dominant Hand }=-11.325+(0.925 * \text { LBM })
$$

Formula 3. Formula for predicting the manual prehensile force (dominant hand) from the LBM determined by impedance.

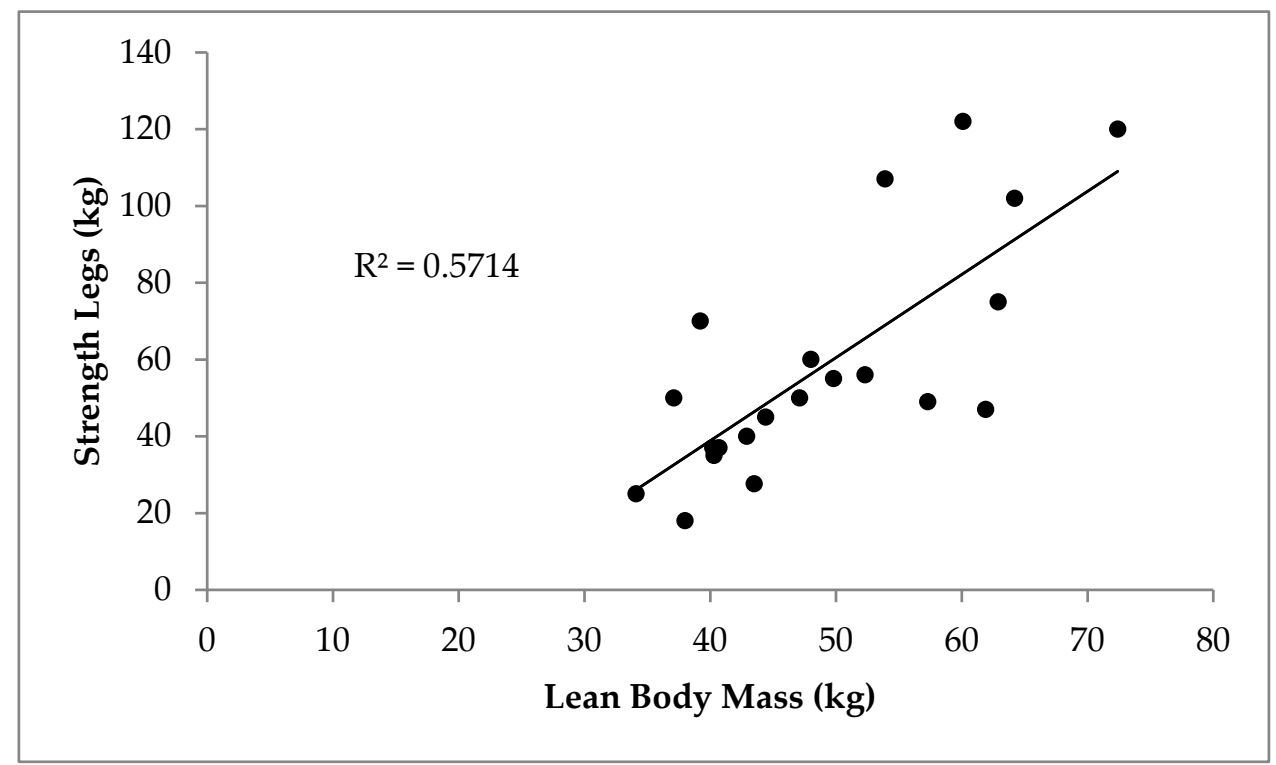

Figure 2. Relationship between the leg strength and LBM of the person.

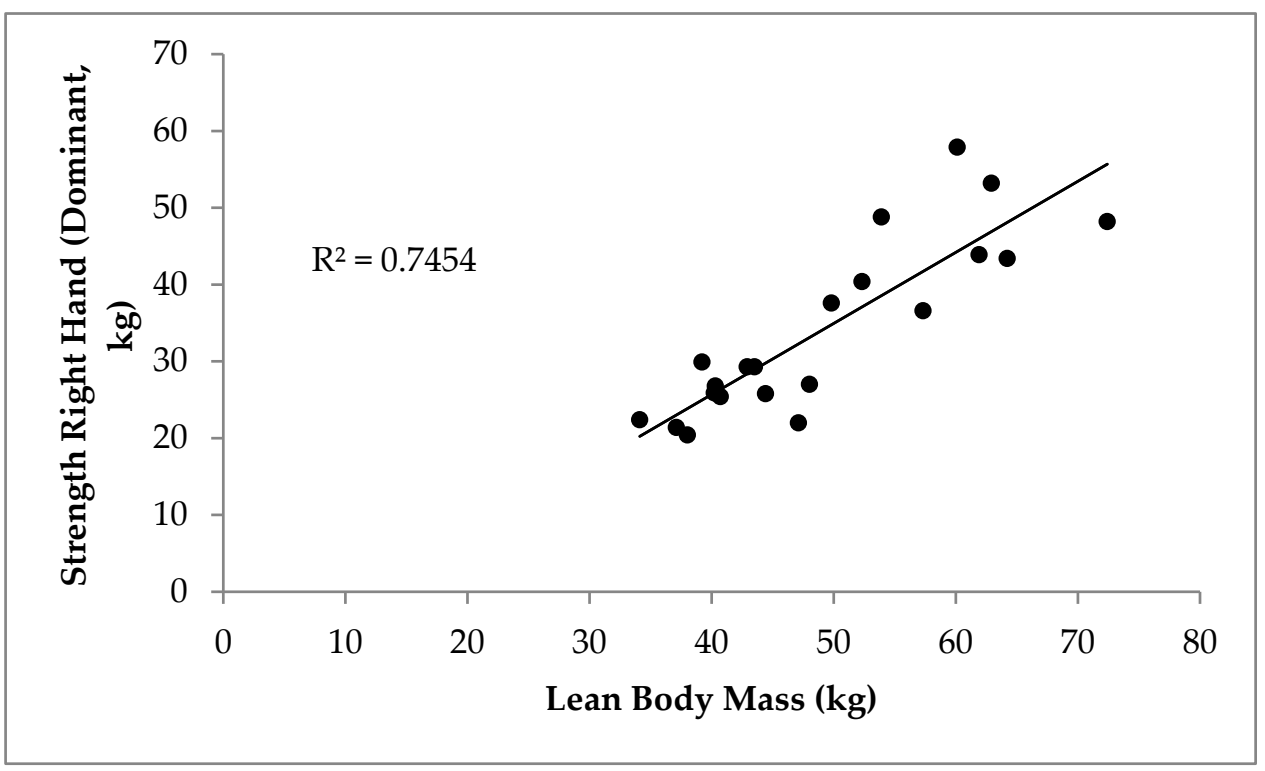

Figure 3. Relationship between the dominant hand strength and the LBM of the person. 


\section{Discussion}

The objective of this study was to determine the relationships between the leg and arm strength, body composition and balance performance of elderly people. The results showed that there are strong relationships between these variables. On the one hand, LBM has a strong relationship with both manual prehensile strength and the lower limbs. This result was mainly caused by the relationship between larger muscle mass and strength parameters [26], and in addition, this force can cause a better balance capacity, as shown in a previous study [6]. In the present study, this relation had a correlation coefficient of $\mathrm{r}=0.49$, and in the study by Castillo-Rodríguez and Chinchilla Minguet, the coefficient was 0.52 [26].

Several studies have confirmed that low muscle strength, both in the legs and in a manual grip, can be a strong and independent predictor of earlier mortality in older people [32,33]. Manual grip strength is also suggested by scientists as an indicator of sarcopenia [34], which is characterized by a loss of muscle mass. Sarcopenia is common in older people, and its incidence increases with age [35]. Grip strength is currently much easier to measure, thus has greater potential than would isokinetic dynamometry for incorporating into clinical practice [36]. Nonetheless, the relationship between muscle strength and LBM (whole-body or regional) is well stated [37]. This relationship has been found to be stronger $\left(\mathrm{R}^{2}=0.70\right)$ when the leg strength is not isometric, but isotonic [38]. In our study, the relationship between LBM and the isometric force reached a mean statistical force of $\left(R^{2}=0.57\right)$.

For these reasons, physical activity is recommended and considered a preventive factor for health issues; with healthy nutritional habits, it can improve physical ability and body composition [27]. The type of physical activity must also be chosen by each person based on their level of enjoyment [39]. In this way, there is a high probability that the person will not abandon the practice and will be motivated to perform the activity frequently $[39,40]$.

This study presents a series of limitations. First, regarding the sample size, it is very challenging to recruit for a study a large number of people over 60 years old who do not have pathologies such as hypertension and diabetes, which affect the results of physical tests in part due to the benefits of the medication consumed; $33 \%$ of the Spanish population over 60 years old suffer from hypertension [41]. In addition, diabetes mellitus causes cognitive damage that worsens coordination skills, such as balance [42]. Second, studies with a larger number of variables or analyses of other health-related capacities should be conducted to determine additional benefits of having more LBM, specifically regarding aerobic resistance or range of movement (flexibility), which were not studied in this manuscript. Finally, a physical activity intervention program should be developed and tested to determine whether the effect observed in the pretest is maintained or improved in the posttest, which may lead to more robust conclusions.

\section{Conclusions}

The main findings of this study showed that physical abilities, specifically strength and the ability to balance, are directly related to the body composition of older people, especially their LBM. The LBM of the elderly people evaluated accounted for $57 \%$ and $75 \%$ of the strength in their legs and in their dominant hand, respectively. For these reasons, the population over 60 years of age is encouraged to participate in physical activity programs to improve their physical and coordinative abilities and therefore improve their body composition, specifically their LBM. In addition, this improvement in LBM will increase their basal metabolism, causing a decrease in their risk for obesity and other related pathologies. The results of this investigation should be taken into account with caution for two reasons. The first reason is the sample limitation; the second reason is the peculiarity of the sample consisting entirely of healthy subjects who do not ingest medications. As a practical application, specifically, the objective of this manuscript was to find relationships of body composition variables with variables extracted from physical tests, as well as to determine how strength (physical quality) influences balance (coordinative quality). If the adult population is able to practice physical activity and reach old age with reduced risk factors, this physical condition will have a positive impact on the sarcopenia process 
and on the functionality and independence of the elderly. Strength, balance and fat-free mass (muscle and bone) are responsible for a person's functionality. Furthermore, these predictive models can be used in coordination by medics, therapists and experts in physical education in the management and control of the load during exercise sessions, as well as for the estimation of the muscular strength of the whole body with satisfactory precision that can report the benefits mentioned.

Author Contributions: Conceptualization, A.C.-R. and W.O.-O.; methodology, J.L.C.-M.; software, R.S.M.; validation, R.S.M., J.L.C.-M. and W.O.-O.; formal analysis, A.C.-R.; investigation, A.C.-R.; resources, R.S.M.; data curation, J.L.C.-M.; writing-original draft preparation, W.O.-O. and A.C.-R.; writing-review and editing, R.S.M.; visualization, J.L.C.-M.; supervision, A.C.-R.; project administration, R.S.M. All authors have read and agree to the published version of the manuscript.

Funding: This research received no external funding.

Acknowledgments: We would like to thank the Escola Superior de Educaçao and the Instituto Polictecnico de Coimbra (Portugal) for its reception and enrichment during the stay.

Conflicts of Interest: The authors declare no conflict of interest.

\section{References}

1. Gasque, P.; Conejo, R.; De Francisco Pascual, J.L.; Lam, A.; Novella, J. Características basales y funcionales de una población que inicia un programa de ejercicio físico. Selección 2005, 14, 108-119.

2. American College of Sports Medicine. Position Stand. The recommended quantity and quality of exercise for developing and maintaining cardiorespiratory and muscular fitness, and flexibility in healthy adults. Med. Sci. Sports Exerc. 1998, 30, 975-991.

3. Fernández-García, J.C.; Alvero-Cruz, J.R.; Alvarez Carnero, E.; Barrera-Expósito, J.; Carrillo de Albornoz-Gil, M.; Martin-Fernández, M.C. Estimación de la composición corporal en personas mayores. II International Congress of Physical Activity in elderly. In Consejería de Turismo, Comercio y Deporte; Instituto Andaluz del Deporte: Malaga, Spain, 2007.

4. Regidor, E.; Gutiérrez-Fisac, J.L.; Alfaro, M. Indicadores de Salud 2009. In Evolución de los Indicadores del Estado de Salud en España y su Magnitud en el Contexto de la Unión Europea; Ministerio de Sanidad y Política Social: Madrid, Spain, 2009.

5. Zhang, J.; Feldblum, P.J.; Fortney, J.A. Moderate physical activity and bone density among perimenopausal women. Am. J. Public Health 1992, 82, 736-738.

6. Castillo-Rodríguez, A.; Chinchilla-Minguet, J.L. Cardiovascular program to improve physical fitness in those over 60 years old-pilot study. Clin. Interv. Aging 2014, 9, 1269-1275. [CrossRef]

7. Bae, C.Y.; Kang, Y.G.; Suh, Y.S.; Han, J.H.; Kim, S.S.; Shim, K.W. A model for estimating body shape biological age based on clinical parameters associated with body composition. Clin. Interv. Aging 2013, 8, 11-18.

8. Poehlman, E.T.; Toth, M.J.; Fishman, P.S.; Vaitkevicius, P.; Gottlieb, S.S.; Fisher, M.L.; Fonong, T. Sarcopenia in aging humans: The impact of menopause and disease. J. Gerontol. A Biol. Sci. Med. Sci. 1995, 50, 73.

9. He, Q.; Heo, M.; Heshka, S.; Wang, J.; Pierson, R.N., Jr.; Albu, J.; Gallagher, D. Total body potassium differs by sex and race across the adult age span. Am. J. Clin. Nutr. 2003, 78, 72-77.

10. Katula, J.A.; Sipe, M.; Rejeski, W.J.; Focht, B.C. Strength training in older adults: An empowering intervention. Med. Sci. Sports Exerc. 2006, 38, 106-111.

11. Gallagher, D.; Visser, M.; De Meersman, R.E.; Sepúlveda, D.; Baumgartner, R.N.; Pierson, R.N.; Heymsfield, S.B. Appendicular skeletal muscle mass: Effects of age, gender, and ethnicity. J. Appl. Physiol. 1997, 83, 229-239.

12. Peake, J.; Della Gatta, P.; Cameron-Smith, D. Aging and its effects on inflammation in skeletal muscle at rest and following exercise-induced muscle injury. Am. J. Physiol. Regul. Integr. Comp. Physiol. 2010, $298,1485-1495$.

13. Colado, J.C.; Garcia-Masso, X.; Rogers, M.E.; Tella, V.; Benavent, J.; Dantas, E.H. Effects of aquatic and dry land resistance training devices on body composition and physical capacity in postmenopausal women. J. Hum. Kinet. 2012, 32, 185-195.

14. Sorkin, J.D.; Muller, D.C.; Andres, R. Longitudinal change in height of men and women: Implications for interpretation of the body mass index: The Baltimore Longitudinal Study of Aging. Am. J. Epidemiol. 1999, 150, 969-977. 
15. Short, K.R.; Vittone, J.L.; Bigelow, M.L.; Proctor, D.N.; Nair, K.S. Age and aerobic exercise training effects on whole body and muscle protein metabolism. Am. J. Physiol. Endocrinol. Metab. 2004, 286, 92-101.

16. Idler, N.; Teuner, C.M.; Hunger, M.; Holle, R.; Ortlieb, S.; Schulz, H.; von Berg, A. The association between physical activity and healthcare costs in children-results from the GINIplus and LISAplus cohort studies. BMC Public Health 2015, 15, 437.

17. Arriscado, D.; Muros, J.J.; Zabala, M.; Dalmau, J.M. Relationship between physical fitness and body composition in primary school children in northern Spain (Logroño). Nutr. Hosp. 2014, 30, 385-394.

18. Correa Rodríguez, M.; Rueda Medina, B.; González Jiménez, E.; Navarro Pérez, C.F.; Schmidt-RioValle, J. The levels of bone mineralization are influenced by body composition in children and adolescents. Nutr. Hosp. 2014, 30, 763-768.

19. Kelley, G.A.; Kelley, K.S.; Pate, R.R. Effects of exercise on BMI z-score in overweight and obese children and adolescents: A systematic review with meta-analysis. BMC Pediatr. 2014, 14, 225.

20. Ekelund, U.; Anderssen, S.A.; Froberg, K.; Sardinha, L.B.; Andersen, L.B.; Brage, S. European Youth Heart Study Group. Independent associations of physical activity and cardiorespiratory fitness with metabolic risk factors in children: The European youth heart study. Diabetologia 2007, 50, 1832-1840.

21. Morales-Suárez-Varela, M.M.; Clemente-Bosch, E.; Llopis-González, A. Relationship between the level of physical activity and markers of cardiovascular health in Valencian adolescents (Spain). Arch. Argent. Pediatr. 2013, 111, 398-404.

22. Voss, C.; Sandercock, G.; Higgins, J.W.; Macdonald, H.; Nettlefold, L.; Naylor, P.J.; McKay, H. A cross-cultural comparison of body composition, physical fitness and physical activity between regional samples of Canadian and English children and adolescents. Can. J. Public Health 2014, 105, 245-250.

23. López Sánchez, G.F.; López Sánchez, L.; Díaz Suárez, A. Efectos de un programa de actividad física en la condición física de escolares con TDAH. Revista Iberoamericana de Ciencias de la Actividad Física y el Deporte 2014, 3, 24-37.

24. Ortega, F.B.; Ruiz, J.R.; Castillo, M.J. Physical activity, physical fitness, and overweight in children and adolescents: Evidence from epidemiologic studies. Endocrinol. Nutr. 2013, 60, 458-469.

25. Andreasen, C.H.; Andersen, G. Gene-environment interactions and obesity-Further aspects of genome wide association studies. Nutrition 2009, 25, 998-1003.

26. Fernández-García, J.C.; Castillo-Rodríguez, A.; Onetti-Onetti, W. Influencia del sobrepeso y la obesidad sobre la fuerza en la infancia. Nutr. Hosp. 2019, 36, 1055-1060.

27. Onetti, W.; Álvarez-Kurogi, L.; Castillo-Rodríguez, A. Adherencia al patrón de dieta mediterránea y autoconcepto en adolescentes. Nutr. Hosp. 2019, 36, 658-664.

28. Tercedor Sánchez, P. Actividad Física, Condición Física y Salud; Wanceulen Editorial Deportiva: Sevilla, Spain, 2001.

29. WMA Declaration of Helsinki-Ethical Principles for Medical Research Involving Human Subjects. Available online: http://www.wma.net/en/30publications/10policies/b3/index.html (accessed on 1 July 2016).

30. Mohan, V.; Shafiqah, N.; Shamsaimon, B.; Izzat, M.; Japri, B.; Effendi, N. Fore arm circumference and hand length predicts maximal hand grip strength among Malaysian population. Middle East J. Sci. Res. 2014, 21, 634-639.

31. Johnson, B.L.; Nelson, J.K. Practical Measurements for Evaluation in Physical Education, 4th ed.; Macmillan: Minneapolis, MN, USA, 1979.

32. Newman, A.B.; Kupelian, V.; Visser, M.; Simonsick, E.M.; Goodpaster, B.H.; Kritchevsky, S.B. Strength, but not muscle mass, is associated with mortality in the health, aging and body composition study cohort. J. Gerontol. Biol. Sci. 2006, 61, 72-77.

33. Ruiz, J.; Sui, X.; Lobelo, F.; Morrow, J.; Allen, W.; Jackson, J.A. Association between muscular strength and mortality in men: Prospective cohort study. BMJ J. 2008, 337, 1-9.

34. Lauretani, F.; Russo, C.R.; Bandinelli, S.; Bartali, B.; Cavazzini, C.; Di Iorio, A.; Ferrucci, L. Age-associated changes in skeletal muscles and their effect on mobility: An operational diagnosis of sarcopenia. J. Appl. Physiol. 2003, 95, 1851-1860.

35. Iannuzzi-Sucich, M.; Prestwood, K.M.; Kenny, A.M. Prevalence of sarcopenia and predictors of skeletal muscle mass in healthy, older men and women. J. Gerontol. Biol. Sci. 2002, 57, 772-777.

36. Rantanen, T.; Guralnik, J.M.; Foley, D.; Masaki, K.; Leveille, S.; Curb, J.D.; White, E. Midlife hand grip strength as a predictor of old age disability. JAMA 1999, 281, 558-560. 
37. Guimarães, B.R.; Pimenta, L.D.; Massini, D.A.; Dos Santos, D.; da Cruz Siqueira, L.O.; Simionato, A.R.; Pessôa Filho, D.M. Muscle strength and regional lean body mass influence on mineral bone health in young male adults. PLOS ONE 2018, 13, 1-13.

38. Raso, V.; Cassilhas, R.C.; Santana, M.G.D.; Boscolo, R.A.; Viana, V.A.R.; Grassmann, V.; Mello, M.T.D. Predictors of muscle strength in older individuals. Med Express 2016, 3, 1-8.

39. Castillo-Rodriguez, A.; Onetti-Onetti, W.; Chinchilla-Minguet, J.L. Perceived Quality in Sports Centers in Southern Spain: A Case Study. Sustainability 2019, 11, 3983.

40. Onetti-Onetti, W.; Castillo-Rodríguez, C.L.; Castillo-Rodríguez, A. Assessment of elderly people characteristics and their relationship with the perceived quality of sport management. Revista Iberoamericana de Ciencias de la Actividad Física y el Deporte 2018, 7, 110-118.

41. Gijón-Conde, T.; Gorostidi, M.; Camafort, M.; Abad-Cardiel, M.; Martín-Rioboõ, E.; Morales-Olivas, F.; De La Sierra, A. Documento de la Sociedad Española de Hipertensión-Liga Española para la Lucha contra la Hipertensión Arterial (SEH-LELHA) sobre las guías ACC/AHA 2017 de hipertensión arterial. Hipertens Riesgo Vasc. 2018, 35, 119-129.

42. Bozanic, A.; Toro, P.; Formiga, F. Proyecto DIABDEM: Estudio piloto de la prevalencia de deterioro cognitivo en diabetes mellitus en 2 países hispánicos. Rev. Esp. Geriatr. Gerontol. 2019, 54, 339-345.

(C) 2020 by the authors. Licensee MDPI, Basel, Switzerland. This article is an open access article distributed under the terms and conditions of the Creative Commons Attribution (CC BY) license (http://creativecommons.org/licenses/by/4.0/). 